\title{
Contact Stress Analysis of Spur Gear Under the Different Rotational Speed by Theoretical and Finite Element Method
}

\author{
Jwan Khalil Mohammed ${ }^{1}$, Younis Khalid Khdir2, Safeen Yaseen Kasab ${ }^{3}$ \\ 1,2Technical Engineering College, Erbil Polytechnic University (EPU), Erbil, Kurdistan Region - Iraq \\ ${ }^{3}$ College of Engineering, Salahaddin University (SU), Erbil, Kurdistan Region - Iraq
}

\begin{abstract}
In this study that spur gears are chosen, contact stress of spur gear is presented under the effect of rotational speed. Three-dimensional simulation of dynamic analysis of gears designed and modeled using ANSYS software. The dynamic analysis included in the determination of dynamic stresses analysis. Contact stress is theoretically calculated and analyzed and numerically estimated using both Hertzian mathematical model and finite element method respectively. Different values of rotational speed used to study its effect on contact stress. Both methods compared by evaluating the percentage error of contact stress, and the modeling of the spur gear and stress analysis of spur gear carried out using SOLID WORK and ANSYS V14, respectively. The most significant note in this study concludes that increasing speed causes vibration and pitting failure due to repetitions.
\end{abstract}

KEYWORDS : Spur gear, Contact stress, Finite Element Method, ANSYS, Rotational speed, Hertzian model.

\section{INTRODUCTION}

Gear is a cylindrical wheel tooth cut that meshed with another gear for transmitting power from one shaft to another, of which both rotate to opposite directions during motion. Gear can also be defined as a rotational toothed wheel that is attached to a shaft. Gears are typically classified to spur, helical, bevel, double helical, hypoid, crown, pinion and rack, epicyclical, worm gears, etc. In the modern engineering systems, they are practically applied in tremendous industries; from a tiny wristwatches to huge machinery equipment, such as; rolling, automobile, aerospace industry, transmitting machinery, hoisting and marine engines (Narayankar \& Mangrulkar, 2017). Spur gear is the simplest type of gear used for transmitting power because of its straight teeth cut on the rim parallel to the axis of rotation. It is the most common and cost-effectiveness type of gear. Spur gear is used in oscillating sprinklers, electric screwdrivers, windup alarm clocks, clothe dryers and washing machines (Sainath). The contact between two teeth follows the line of action. The driving wheel begins at the tooth root and moves towards the top, while the following wheel moving reversely from top to

Academic Journal of Nawroz University

(AJNU) Volume 7, No 4 (2018).

Regular research paper : Published 21 December 2018

Corresponding author's e-mail : jwan.eng@hotmail.com

Copyright @2017 Jwan Khalil Mohammed¹, Younis Khalid

Khdir2, Safeen Yaseen Kasab ${ }^{3}$.

This is an open access article distributed under the Creative

Commons Attribution License. root, as shown in Fig. 1. When a Contact is placed between the root and the pitch circle of the driving wheel in the first half of the meshing, the friction force moved towards the root of the driving tooth and the rotation counteracts. When the contacted teeth passed through pitch circle, the friction force alters direction and acts to the rolling motion. Also, this direction reverses to the followed teeth. Thus, relative motion is fixed across the contact width but is also changed during the interaction. The schematic diagram of the motion of the spur gear is illustrated in Fig. 1. (Damtie \& Tilahun, 2014).

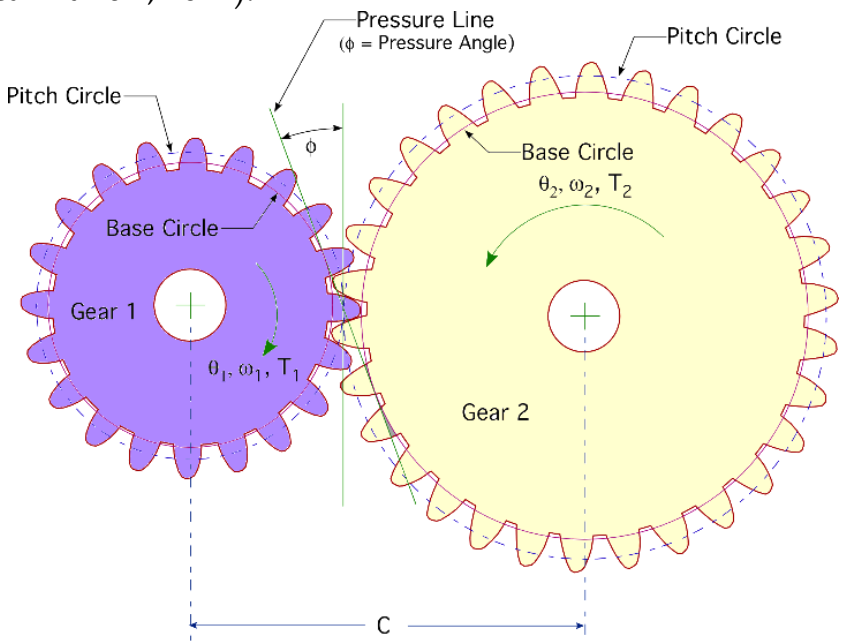

Fig (1) : Schematic diagram of spur gear motion

The main problem in spur gear encountered during rising loads and speeds. By effect of contacting between the two rods at the contact point, it creates a very high 
stress that the material cannot withstand it. Reducing the dynamic effect is the main rewards to help remaining the velocity ratio constant which gives rise to increase stress, noise and vibration (Ravindra, 2013). The Normal or resultant force acts along the pressure line at pitch point that solves both tangential and vertical component in a horizontal and vertical plane. The tangential force component is used to calculate torque and power of spur gear. The contact stress and bending stress are induced on the gear due to the tangential load acts on the gear. If contact stress on the gear is higher than the wear strengths of the gear material, gear failure that would take place called as wear or pitting failure of the gear (Chor \& Pillai, 2015). When loads are applied to the bodies, the point of contact is, elastically deformation, occurs near their surfaces. The highest stresses happen in regions where the lines collected closest together. The highest stress occurs in two locations, when the force acts in contact point and at the fillet area near the base of a tooth. Surface failure of tooth gear generally occurs due to pitting and scoring. Pitting is actually the fatigue failure of the tooth surface due to many repetitions of the stress of gear surface during motion. The primary property of the gear tooth that provides resistance to pitting is the Hardness. In other words, when a pair of teeth is transmitting a power the fatigue failure takes place on the gear teeth during the repetitions of high contact stress, thus pitting occurs (Rajaprabakaran \& Ashokraj, 2013). The other primary cause of gear tooth failure is the existing large tensile stresses in the root fillet of the loaded gear tooth. These stresses decrease the overall gear life and can result in disastrous tooth failure under peak load condition (Abattini, Mirza, \& Pawar, 2017; K. Gupta \& Chatterjee, 2018). The contact stress is calculated by the method of Hertzian equation based on the contact between two cylinders. In addition, the Finite Element Method is used in order to analyze the contact stress. Hassan (2009) and Hwang et. al., (2013) presented a research study for analyzing contact stress among two spur gear teeth various contact positions of gears during rotation. The study developed a platform for plotting a pair of teeth in contact. Through running the platform for rotating each $3^{\circ}$ of pinion from the first position of the contact to the last position of the contact, 10 cases produced. The research represented a sequence position of contact between these two teeth for each case. The graphical results between the position and location of contact during rotation were plotted. Finite element models were made for these cases and stress analysis was done using ANSYS. The both of finite element analysis and Hertzian equation were used for calculating the contact stresses. The finite element method results compared with theoretical calculations (Hassan, 2009; Hwang, Lee, Lee, Han, \& Lee, 2013).
Gupta and Verde explained that the study of contact stress is an important parameter for gear design. Analytical methods for calculating gear contact stresses is studied using Hertz's equations and ANSYS, and the results were compared with Hertzian theory. In their paper, they calculated contact stress for various values of modules and concluded that the module is significant geometrical parameter during the design of gear and observed that contact stress decreases with increasing module. The contact stresses are higher at the pitch point (B. Gupta, Choubey, \& Varde, 2012). Karaveer et. al., (2013) studied the stress analysis of mating teeth of spur gear to calculate maximum contact stress in the gear teeth. The gained results from Finite Element Analysis (FEA) were compared with theoretical values of Hertzian equation. The spur gears used in this research are made from steel and Grey cast iron. Spur gear stress modeled by ANSYS and calculated by both Finite Element Method (FEM) and theoretically using Hertizian equation. The deformations of Grey cast iron and steel were gained as the efficiency of the gear depends on their deformation. The research results showed that the difference between maximum contact stresses calculated from Hertz equation and Finite Element Analysis is very close and is acceptable (Karaveer, Mogrekar, \& Joseph, 2013). Rao et. al., (2015) realized that the key parameter of gear design can be considered where it is contacted stress and deformation. They noticed that when the working stress exceeds the maximum stress, the gears become a failure. They showed that the complex design problem of spur gears for analyzing and modeling require a fine software skill. They compared both methods, concluding that the range of contact stresses and deformation are useful in the selection of material in different applications, which leads to accept the FEM results (P. Rao, Sriraj, \& Farook, 2015). Rao and Vamsi (2016) presented analysis and design of the contact stresses of spur gear in a different value of software tools like pro-e and ANSYS. The ANSYS design for sketching the spur gear is used and analyzed the contact stress in mechanical ANSYS multiphysics (P. S. Rao \& Vamsi, 2016). Some other researchers implemented a finite element model for stress analysis of gear drives based on multi-point constraints see (Gonzalez-Perez \& Fuentes-Aznar, 2017). A finite element model of a gear pair was presented dynamic transmission error (DTE), which was suited to DTE analysis in consideration of gear eccentricities and varying load see (Gonzalez-Perez \& Fuentes-Aznar, 2017). Where some researchers investigated, experimentally and analytically, the influence of pitch deviations on the loading capacity of spur gears (Franulovic, Markovic, Vrcan, \& Soban, 2017). On the other hand, the external spur gear root bending stress studied using ANSYS finite element analysis and strain 
gauge techniques (Lisle, Shaw, \& Frazer, 2017). Recently an optimization variables consisted of the gear module, the face width, the pinion and wheel profile shift coefficients and the number of teeth of the pinion showed by (Miler, Žeželj, Lončar, \& Vučković, 2018). Then many researchers were studied the contact stress of spur gear using finite element method, ANSYS, and theoretical Hertzian equations; some of them were presented the effect of parameters such as changing pressure angle, teeth number, hardening, and/or materials that cause the failure like fatigue or pitting and minimizing the stresses nevertheless; speed ratio is another parameter for reducing the contact stress which causes fatigue failure and reduces the life of gear. Therefore, the aim of this study is to present the effect of rotational speed of gear on contact stress and comparison between the finite element numerical solution by ANSYS and theoretical Hertzian method. In the next section, the theoretical background and mathematical equations of the Hertzian method explained and then the results and discussion showed, while the conclusion of this research presented in the last section.

\section{THEORETICAL BACKGROUND}

On transfer of power between gears takes place at the contact between the acting teeth, the stresses at the contact point can be computed by means of the Hertzian equation. According to the above mentioned theory, the stresses and deformations of curved bodies in contact can be expressed mathematically. A model applied to the gear-two parallel cylinders in contact is shown in Fig. 2 (Quadri \& Dolas, 2015).

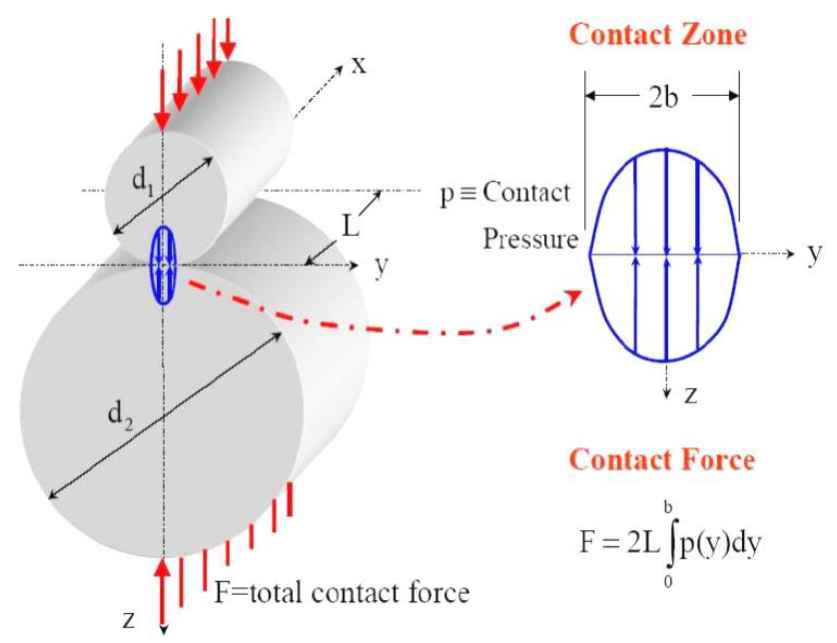

Fig (2) : Hertzian Theory (Quadri \& Dolas, 2015)

Based on the Hertizian theory, the simplest expression of the mathematical equation can be explained as follows, the half-width $b$ is given by the equation : $b=\sqrt{\frac{2 F}{\pi L} \frac{\left(1-v_{1}^{2}\right) / E_{1}+\left(1-v_{2}^{2}\right) / E_{2}}{\left(1 / d_{1}+1 / d_{2}\right)}}$

Assuming that the contacting elements are two cylinders of length $L$ and cylinder diameters $d_{1}$ and $d_{2}$, as shown in Fig. 2, width $2 b$ and length $L$ is face width represents the dimensions of the narrow rectangular area of contact, $F$ is contact force, $v_{1}, v_{2}, E_{1}, E_{2}$ Poisson's ratio and Modulus of elasticity of two materials respectively (Budynas \& Nisbett, 2008; Khan, Mangla, \& Din, 2015), and the distribution of pressure is elliptical, the maximum pressure can be calculated by :

Pressure $=\frac{2 F}{\pi b L}$

The maximum value of contact stress in gear teeth according to the Hertzian equation can be estimated by :

$$
\sigma_{c}=\sqrt{\frac{F}{\pi L} \frac{\left[1 / r_{1}+1 / r_{2}\right]}{\left[\left(1-v_{1}^{2}\right) / E_{1}+\left(1-v_{2}^{2}\right) / E_{2}\right]}}
$$

Where, $L$ Face width of pinion in $\mathrm{mm}, r_{1}, r_{2}$ represents the radius of the two gears in $\mathrm{mm}$.

\section{DETERMINATION OF CONTACT STRESS BY HERTZIAN EQUATION}

The contact stress equation for a pair of teeth contacting in contact point, the $r_{1}, r_{2}$ should be replaced by the radius of curviture at the pitch point (Khan et al., 2015).

Therefore

$r_{1}=\frac{d_{p p} \sin \phi}{2}$ and $r_{2}=\frac{d_{p g} \sin \phi}{2}$

Where $\phi$ repsents the pressure angle, $d_{\mathrm{pp}}, d_{\mathrm{pg}}$ represents the pitch circle diameter of pinion and gear respectively. A pair of gears have the same geometry so:

$d_{p p}=d_{p g}=d_{p}$

$d_{\mathrm{p}}$ represent the Pitch circle diameter in $\mathrm{mm}$.

so, $r_{1}=r_{2}=r=\frac{d_{p} \sin \phi}{2}=r_{p} \sin \phi$

hence, $\sigma_{c}^{2}=\frac{F E}{\pi L r_{p}(1-v) \sin \phi}$

$F=\frac{F_{t}}{\cos \phi}$

$\sigma_{c}^{2}=\frac{E}{\pi(1-v)}\left[\frac{F_{t}}{L r_{p} \sin \phi \cos \phi}\right]$

Same material is used for both pinion and gear such as structural steel.

so, $E_{1}=E_{2}=200 \mathrm{GPa}$, and $v_{1}=v_{2}=0.3$ 
$\sigma_{c}=301,572\left[\frac{F_{t}}{L r_{p} \sin \phi \cos \phi}\right]^{1 / 2}$

The contact stress can be evaluated mathematicaly by equation 7 for structural steel for a pair of gear teeth (gear and pinion have same geometry and dimentions). The applied tourque on the gear can be determined by:

$T=F_{t} \times \frac{d_{p}}{2}$

The tangential component of the resultant force can be determined as:

$$
F_{t}=\frac{2 T}{d_{p}}
$$

$F_{\mathrm{t}}$ is the tangential component of the resultant force.

The maximum allowable contact stress after considering the safety factor between the pinion and the gear can be expressed by:

$$
\sigma_{c a}=\frac{\sigma_{c}}{S . F}
$$

Where S.F. is safety factor and $\sigma_{\mathrm{ca}}$ is the maximum allowable stress.

and the power transmitted $P$ in $k W$ between the two gears can be estimated by the fillowing equation:

$\mathrm{P}=T \times \omega$

Where $\omega$ is the angular velocity and then:

$\mathrm{P}=\frac{2 \pi n_{p} T}{60 \times 10^{6}}$

Where $T$ represents the transmitted torque and $n_{\mathrm{p}}$ represents the rotational speed of the pinion (Jabbour \& Asmar, 2015; Karaveer et al., 2013).

The mathematical calculation was made based on the following dimensions of the gear and the pinion, as explained in Table 1.

TABLE (1) : Spur gear and pinion dimensions

\begin{tabular}{|c|c|c|}
\hline Part dimension & Symbol & value \\
\hline No.of teeth & $\mathrm{Z}$ & 20 \\
\hline Pessure angle & $\Phi$ & 20 \\
\hline Module & $\mathrm{M}$ & 6.35 \\
\hline Pitch circle diameter & $\mathrm{d}_{\mathrm{p}}$ & 127 \\
\hline Face width & $\mathrm{L}$ & 25.4 \\
\hline Dedendum circle diameter & $\mathrm{d}_{\mathbf{a}}$ & 139.7 \\
\hline Addendum circle diameter & $\mathrm{d}_{\mathbf{d}}$ & 111.76 \\
\hline
\end{tabular}

All dimensions are in $\mathrm{mm}$

Now, calculating the torque, tangential component of the resultant force and contact stress between the spur gears (pinion and gear) based on the dimensions in Table 1 can be determined by equation 7,8 , and 10 assuming that the power transmitted is $10 \mathrm{KW}$, if the rotational speed is $3500 \mathrm{rpm}$.

$$
\begin{aligned}
& T=27283.7 \mathrm{Nmm} \\
& F_{t}=429.665 \mathrm{~N} \\
& \sigma_{c}=274.0134 \mathrm{MPa}
\end{aligned}
$$

Noting that the safity factor is $\underline{2.8288}$ which is the same value that taken in ANSYS data.

Then the maximum allowable stress can be detemined according to the equation 9.

$$
\sigma_{c a}=96.9 \mathrm{MPa}
$$

\section{DETERMINATION OF contact STRESS IN ANSYS:} 4.1. GEAR MODELING

The 3D gear geometry is designed with the dimensions shown in Table 1 using ANSYS as shown in Fig.3.

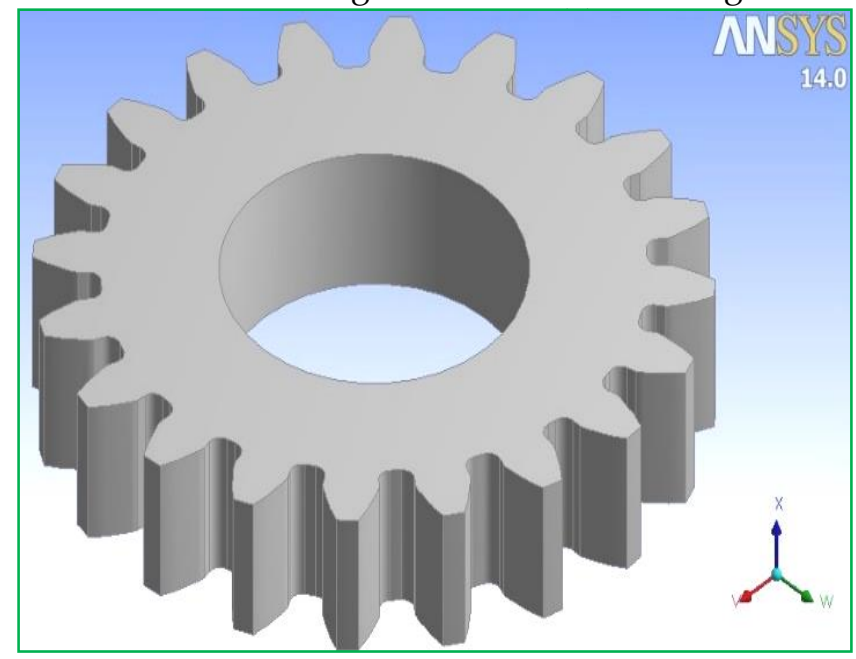

Fig (3) : ANSYS simulated 3D model of spur gear (10)

Static structural preference in ANSYS software for analysis is used. The material properties for the structural considered is steel; the yield strength 250 $\mathrm{MPa}$, ultimate yield strength $460 \mathrm{MPa}$, the poison's ratio is 0.3 and modulus of elasticity as $200 \mathrm{GPa}$. The threedimensional gear modeled by extruding the twodimensional geometry and the contact area between two gears are indicated in Fig. 4.

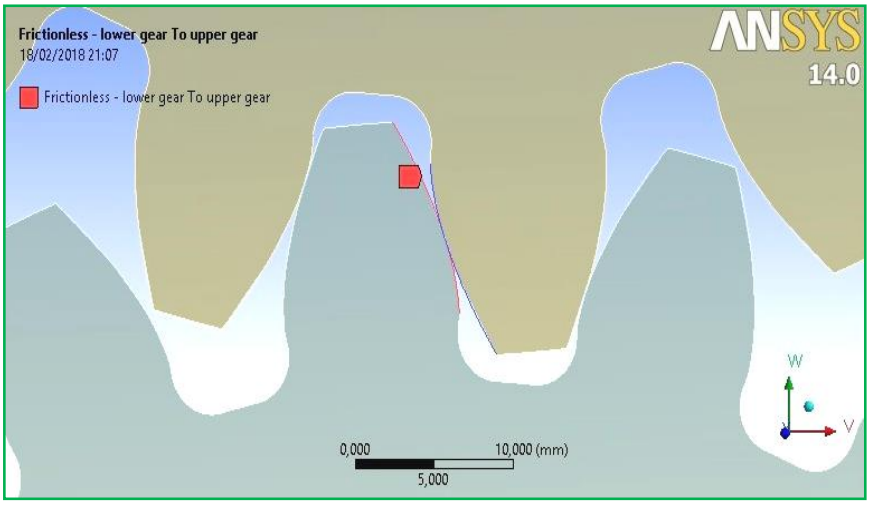

Fig (4) : The contact area between two gears 
The 3D gear is meshed and refined the contact region in order to obtain more acurate results. The mesh type used in this research is free mesh because it can give more accurate results when compared with rectangular type. In Fig. 5, the mesh type and more dense area of the mesh are illustrated, see (Y.-K. Khdir, Kanit, Zaïri, \& Naït-Abdelaziz, 2014, 2015; Y. Khdir, Kanit, Zaïri, \& Nait-Abdelaziz, 2013; Y. K. Khdir, 2016).

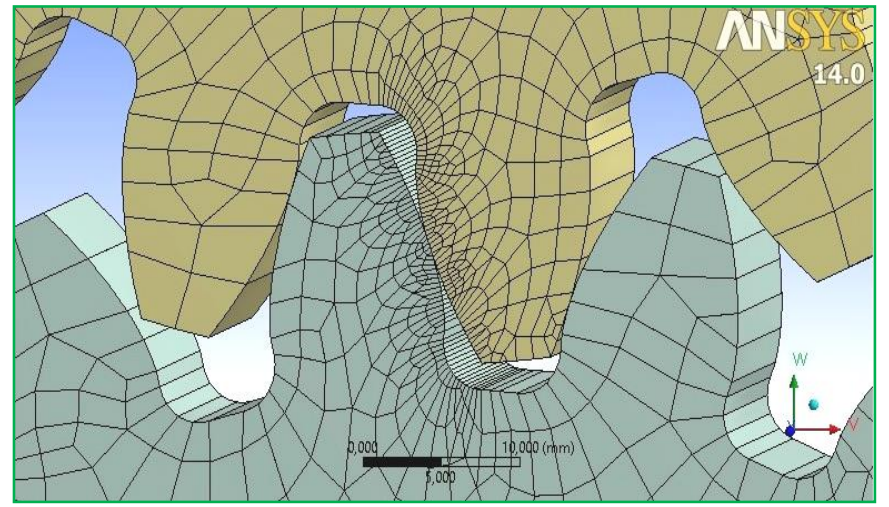

Fig (5) : Meshing technique and the density of mesh of the contact area

\subsection{Finite Element Analysis}

After creating the $3 D$ geometry of the two gears; for the first gear fixed supported is applied and for the second gear frictionless support is considered, see Fig. 6a and $6 \mathrm{~b}$. The boundary conditions applied on the two gears are as follows; the various ranges of moments are applied on the inner rim of upper gear in clokewise direction as shown in Fig. 6c and Rotational velocity is applied on the Z-axis to the fixed center of the rotation repectively in various ranges in counterclockwise direction as showen in Fig. 6d. After applying all the conditions in ANSYS, the minimum and maximum equivalent contact stress can be determined between the two gears. Also, the stress distribution over the contact area of the two gears and the local stress at each point can be predicted.

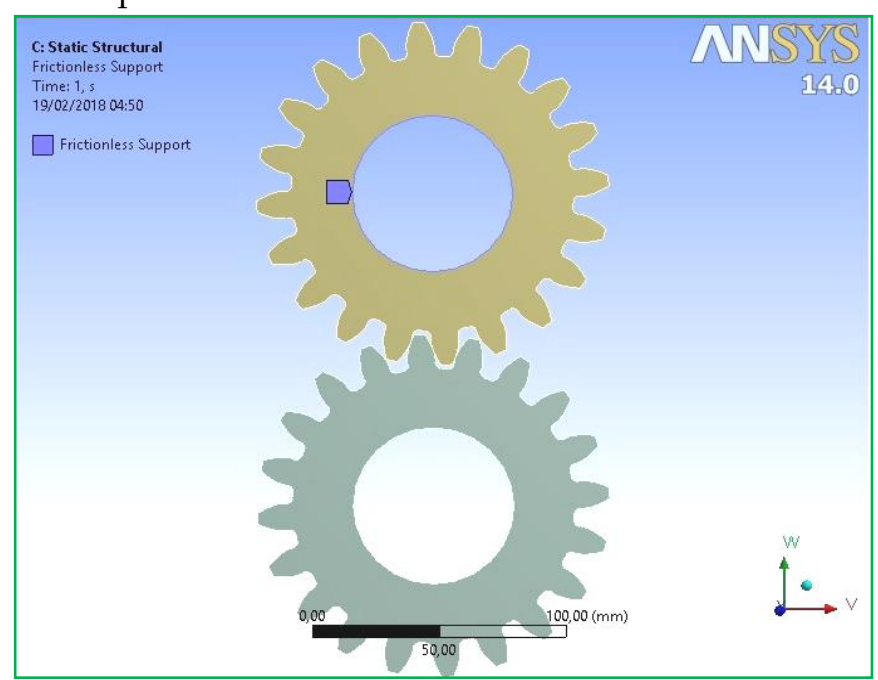

(A) 


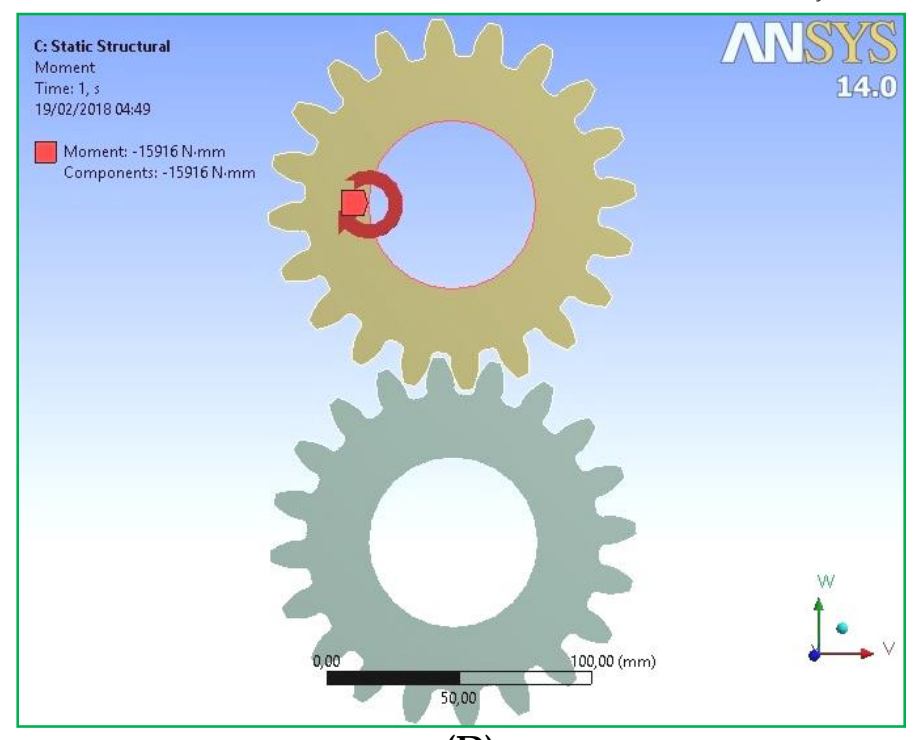

(D)

Fig (6) : The boundary condition of the two gears before running the software

(a) Frictionless support (b) Fixed support (c) Moment and (d) Rotational velocity

\section{RESULT AND DISCUSSION}

Fig. 7 shows the FE solution of the contact stress between the two gears for 6 different cases. For each case the rotational speed is provided with the applied moment. Fig. 7a shows the first case of the simulation which represents case no. 1 , the rotational speed is 3500 $\mathrm{rpm}$, and moment is 27283.7 N.mm. It has noticed that there are different ranges of stress according to the different colors as illustrated in the figure. Based on the software data, the equivalent contact stress is determined which is equal $88.378 \mathrm{MPa}$. This result can be compared with the exact results obtained from the Hertzian equation which is equal to $96.79 \mathrm{MPa}$. Also we can calculate the error percentage according to the below equation:

$$
\text { Error } \%=\frac{\text { Maximum contact stress (FE ANSYS) }- \text { Maximum contact stress (Hertzian) }}{\text { Maximum contact stress (Hertzian) }} \times 100
$$

For the other cases as presented in Fig. 7, there are the exact results of Hertzian equation and the FE results different ranges of stress distribution according to the using ANSYS software are presented in Table 2. value of the rotational speed. The comparison between

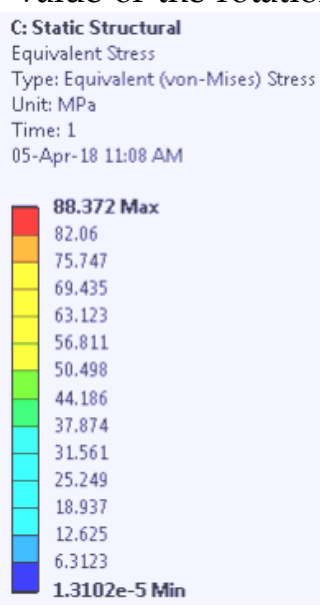

c: Static Structural

Equivalent Stres:

Type: Equivalent (von-Mises) Stress

Unit: MP

05-Apr-18 11:08 AM

\begin{tabular}{|l}
88.372 Max \\
82.06 \\
75.747 \\
69.435 \\
63.123 \\
56.811 \\
50.498 \\
44.186 \\
37.874 \\
31.561 \\
25.249 \\
18.937 \\
12.625 \\
6.3123 \\
$\mathbf{1 . 3 1 0 2 e - 5}$ Min
\end{tabular}

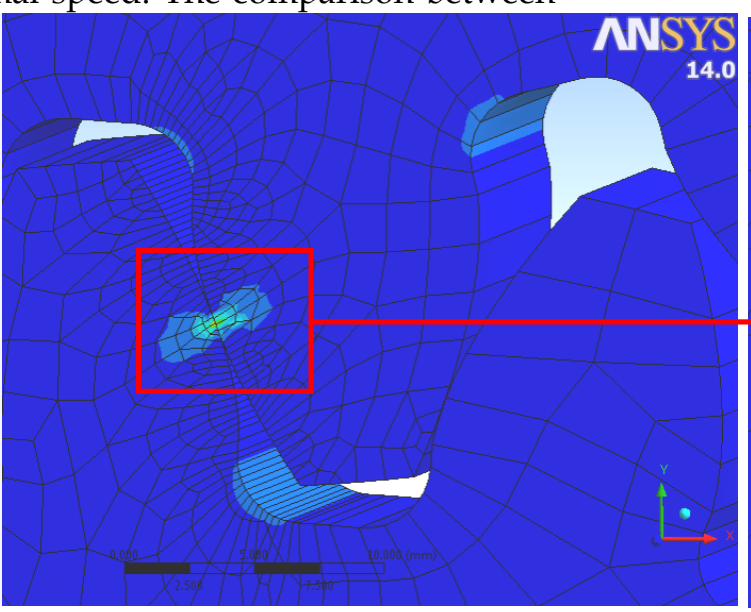

(a)

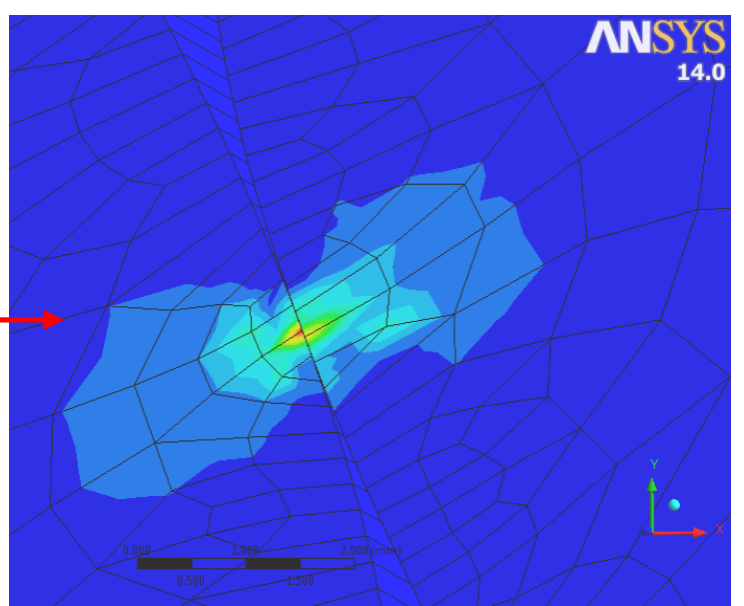




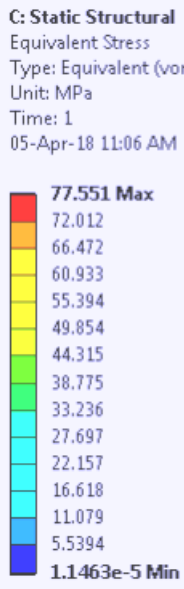

C: Static Structural Equivalent Stress

Type: Equivalent (von-Mises) Stress Unit: $\mathrm{MPa}$

Time: 1

05-Apr-18 11:01 AM

\begin{tabular}{|l}
$\mathbf{6 8 . 9 3}$ Max \\
64.01 \\
59.09 \\
54.16 \\
49.24 \\
44.32 \\
39.39 \\
34.47 \\
29.54 \\
24.62 \\
19.7 \\
14.77 \\
9.848 \\
4.924 \\
\hline $\mathbf{1 . 0 1 9 e - 5}$ Min
\end{tabular}

Fig (7) : Contact stress between the two gears, for different speeds (a) 3500, (b) 4000, and (c) $4500 \mathrm{rpm}$

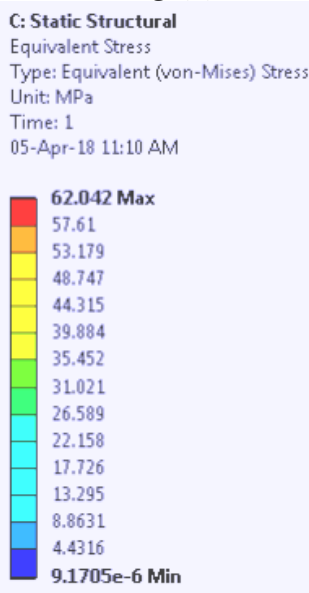

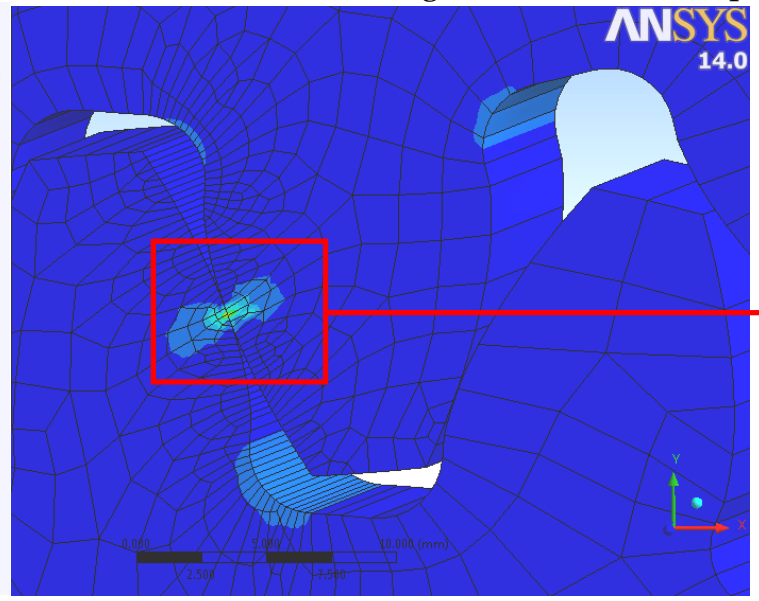

NWSYS

(b)

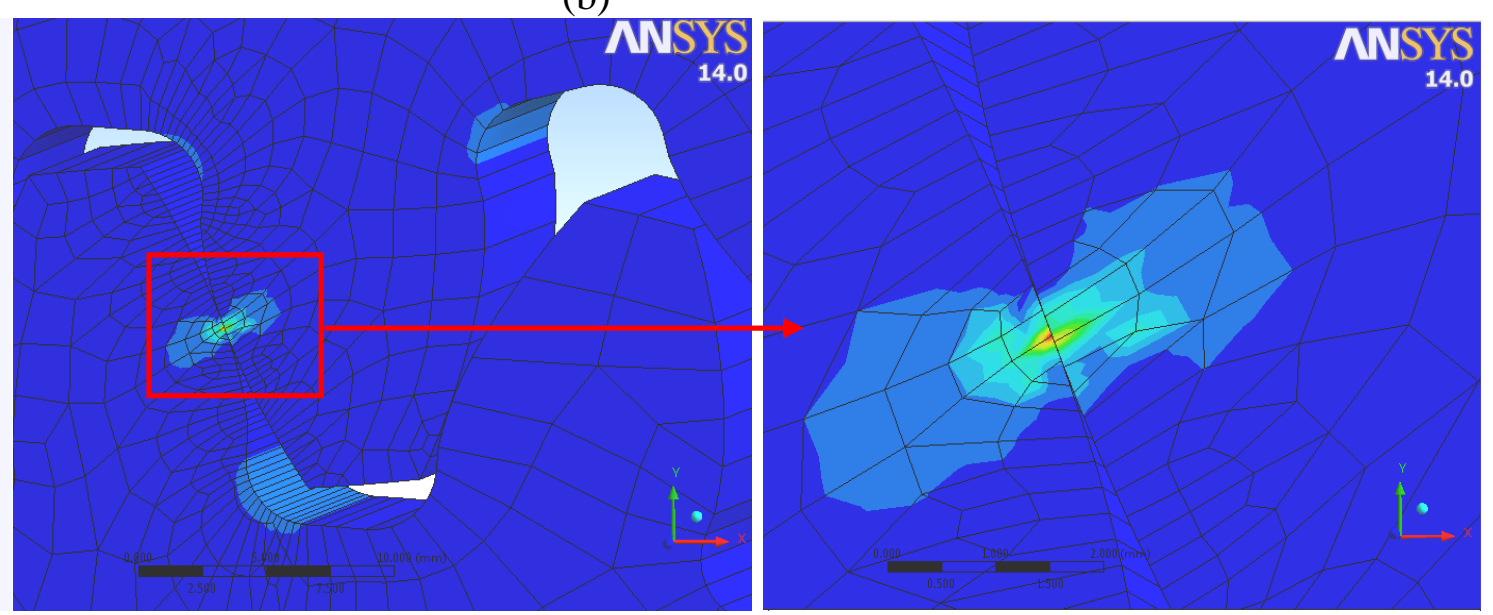

(c)
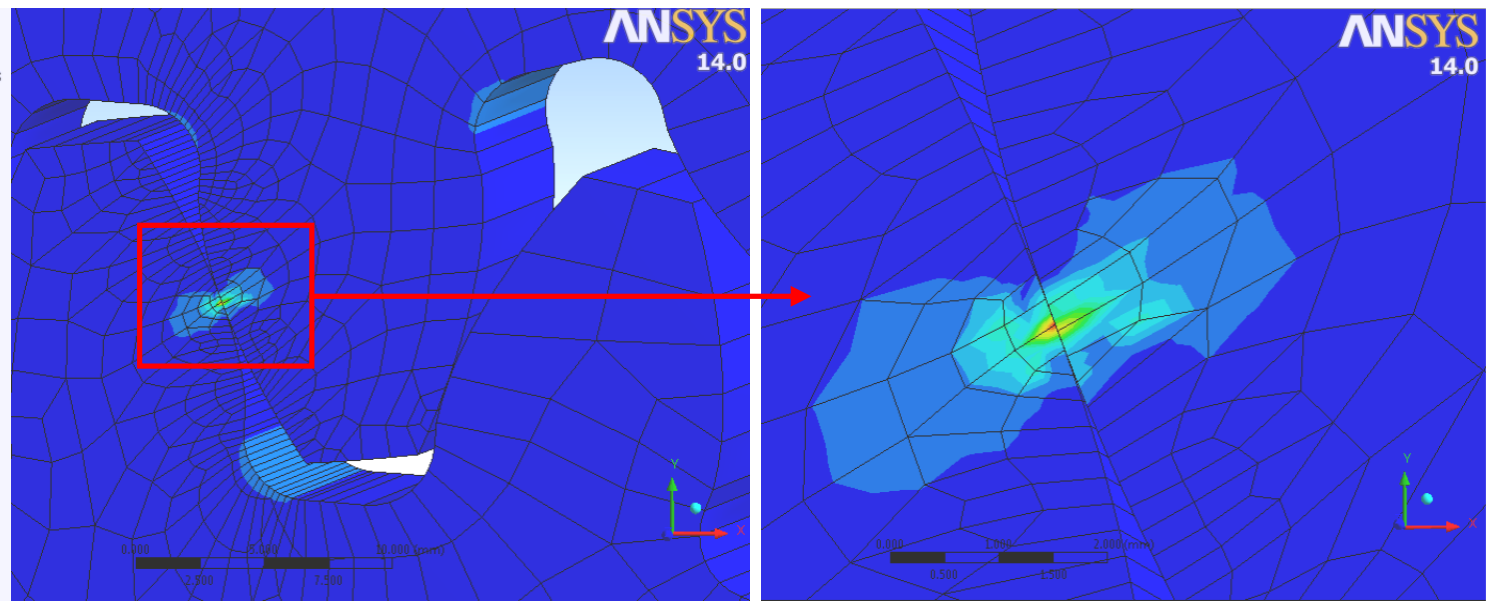


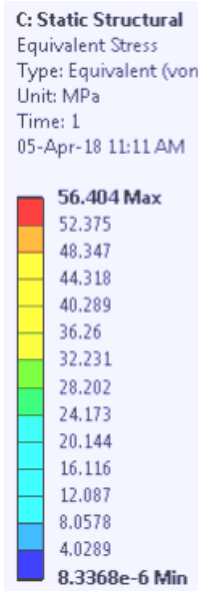

8.3368e-6 Min

C: Static Structural

Equivalent Stress

Type: Equivalent (von-Mises) Stress Unit: $\mathrm{MPa}$

Time: 1

05-Apr-18 11:12 AM

\begin{tabular}{|l}
$\mathbf{5 1 . 7 1}$ Max \\
48.016 \\
44.323 \\
40.629 \\
36.935 \\
33.242 \\
29.548 \\
25.855 \\
22.161 \\
18.468 \\
14.774 \\
11.081 \\
7.3871 \\
3.6936 \\
$7.6422 e-6 ~ M i n$
\end{tabular}

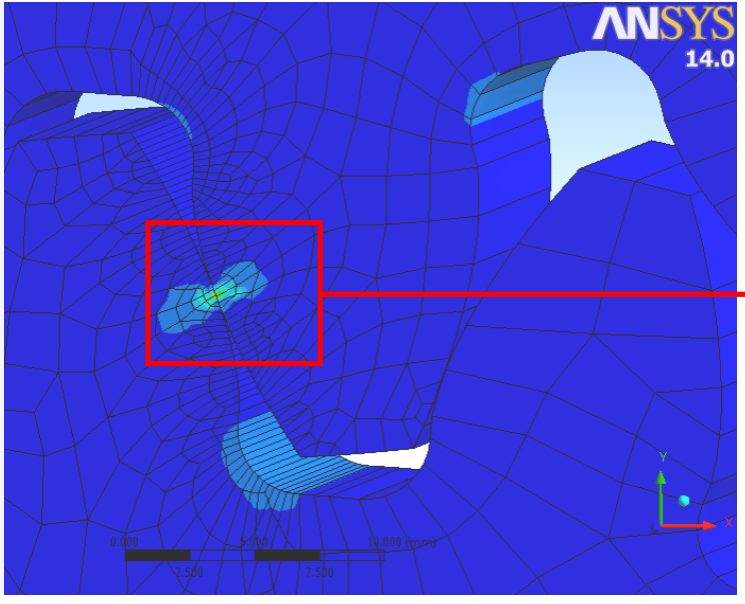

(e)
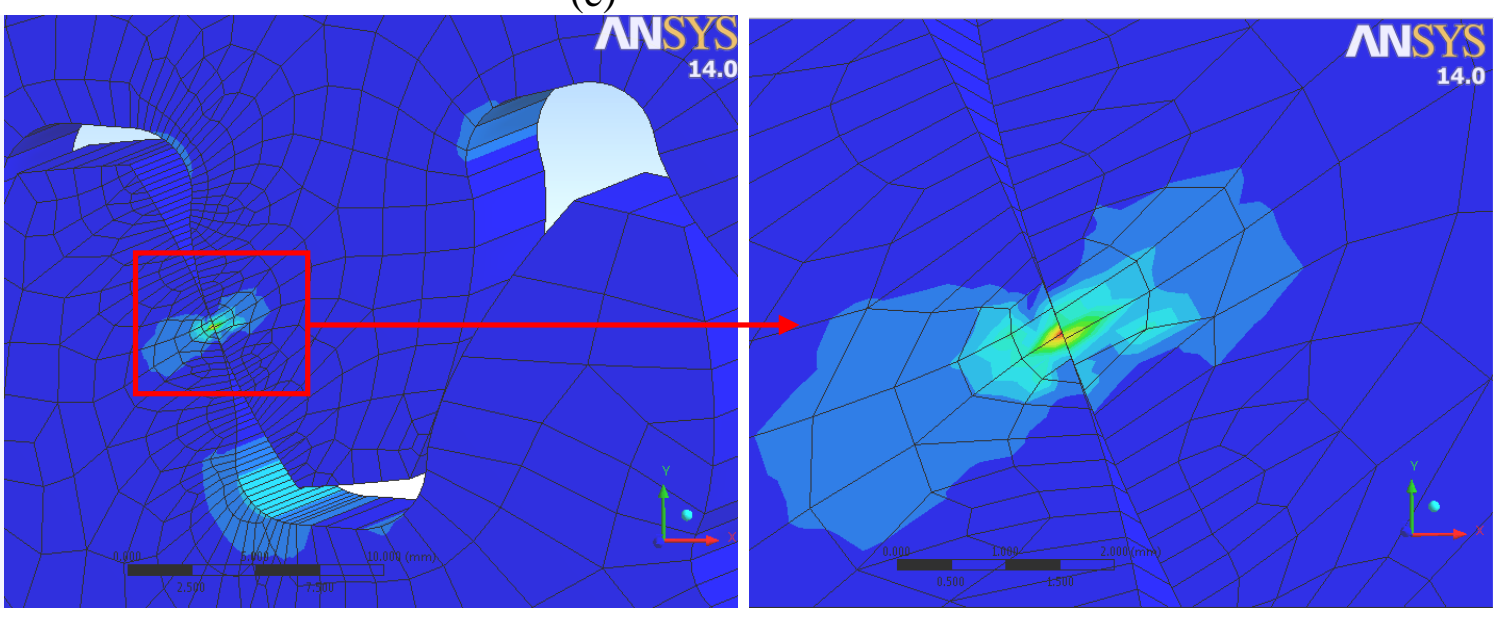

(f)

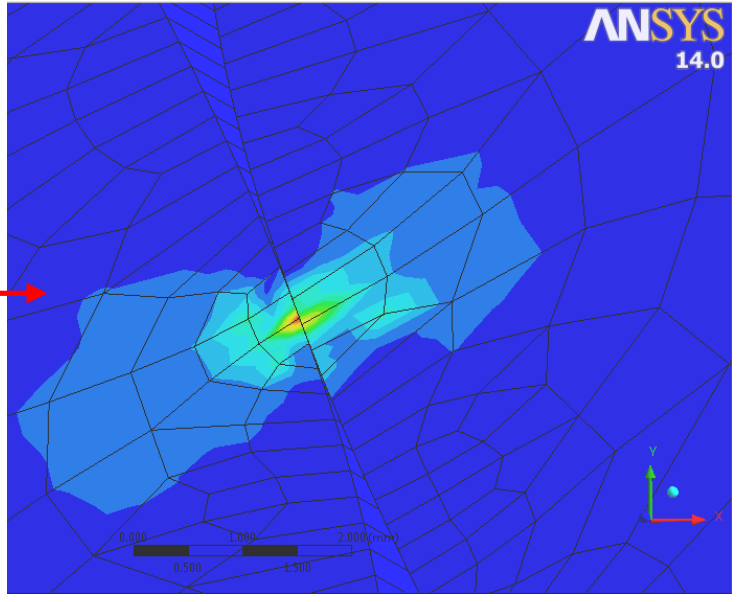

14.0

Fig (7) : Contact stress between the two gears, for different speeds, (d) 5000, (e) 5500, and (f) $6000 \mathrm{rpm}$

TABLE (2) : Maximum contact stress results in ANSYS and Theoretical calculations

\begin{tabular}{|c|c|c|c|c|c|}
\hline No. & $\begin{array}{c}\text { Rotational } \\
\text { speed(rpm) }\end{array}$ & $\begin{array}{c}\text { Applied } \\
\text { moment }\end{array}$ & \multicolumn{2}{|c|}{$\begin{array}{c}\text { Maximum contact stress } \\
M P a\end{array}$} & Error \\
\hline & $R p m$ & Nmm & ANSYS & Hertz & $\%$ \\
\hline 1 & 3500 & 27283.7 & 88.378 & 96.79 & 8.79 \\
\hline 2 & 4000 & 23873.24 & 77.56 & 79.52 & 2.465 \\
\hline 3 & 4500 & 21221 & 68.896 & 66.6 & 3.45 \\
\hline 4 & 5000 & 19098.6 & 62.043 & 56.9 & 9.04 \\
\hline 5 & 5500 & 17362.4 & 56.404 & 49.32 & 14.36 \\
\hline 6 & 6000 & 15915.5 & 51.708 & 43.286 & 19.46 \\
\hline
\end{tabular}

In Fig. 8 the relationship between the contact stress in $M P a$ and the rotational speed $(r p m)$ for the two gears are shown 


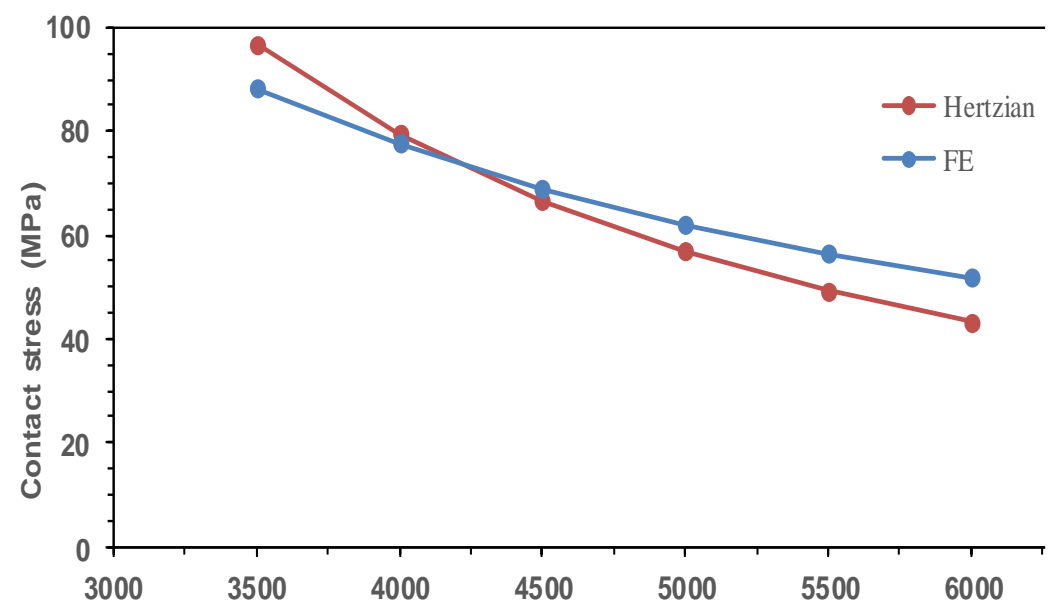

Fig (8) : The relationship between the rotational speed and contact stress

The results of Hertzian equation and finite element analysis for rotational speed obtained by considering different values of (3500 to 6000) rpm as presented in Table 2. The contact stress has been reduced in both methods with increasing rotational speed. When the rotational speed is $3500 \mathrm{rpm}$ the maximum value of contact stress is $96.79 \mathrm{MPa}$, if we use Hertizian equation comparing to the other cases readings. Whereas, this value is reduced up to $88.378 \mathrm{MPa}$ using FE solution using ANSYS for the same value of speed, with the error percentage of $8.79 \%$. However, there is no significant difference between Hertzian equation FE result when the rotational speed increased from 5000 $\mathrm{rpm}$ to $6000 \mathrm{rpm}$ which is the error percentage increased from $9 \%$ to $14.36 \%$, and $19.46 \%$. These results show a degree of agreement with the percentage error $2.465 \%$ and $3.45 \%$ at $4000 \mathrm{rpm}$ and $4500 \mathrm{rpm}$ that is acceptable.

\section{CONCLUSION}

In this research the following points are concluded:

- The influence of increasing speed on contact stress that is due to increase the vibration of gear teeth and cause pitting is caused by the repetition of the contact between teeth mating, and it leads to the dynamic body force and is more effective.

- There is an acceptable error percentage between exact and FE solution.

- When comparing between the exact and FE results, it is possible to use ANSYS to analyze the effect of the other variables.

- The ANSYS solver is capable to evaluate a very difficult cases, and it is possible to use FE method to study different materials and sizes.

- The location of the maximum and minimum stress can be predicted using FE method.

- According to the data of this research the more acceptable spur gear speed is $4000-4500 \mathrm{rpm}$.

\section{REFERENCES}

1. Abattini, N. B., Mirza, M. M., \& Pawar, P. V. (2017). Effect of Change of Spur Gear Tooth Parameter on Contact stress. International Research Journal of Engineering and Technology, 4(6), 1259-1263.

2. Budynas, R. G., \& Nisbett, J. K. (2008). Shigley's mechanical engineering design (Vol. 8): McGraw-Hill New York.

3. Chor, P. M., \& Pillai, P. (2015). Spur Gear Contact Stress Analysis and Stress Reduction by Experiment Method. International Journal of Engineering Research and General Science., 3(3), 126-135.

4. Damtie, S., \& Tilahun, D. (2014). Contact stress analysis of involute spur gear by Finite Element Method (FEM). Zede Journal, 32, 33-40.

5. Franulovic, M., Markovic, K., Vrcan, Z., \& Soban, M. (2017). Experimental and analytical investigation of the influence of pitch deviations on the loading capacity of HCR spur gears. Mechanism and Machine Theory, 117, 96-113.

6. Gonzalez-Perez, I., \& Fuentes-Aznar, A. (2017). Implementation of a finite element model for stress analysis of gear drives based on multi-point constraints. Mechanism and Machine Theory, 117, 35-47.

7. Gupta, B., Choubey, A., \& Varde, G. V. (2012). Contact stress analysis of spur gear. International Journal of Engineering Research and Technology, 1(4), 1-7.

8. Gupta, K., \& Chatterjee, S. (2018). of Design and Material Selection of a Spur gear pair for Solar Tracking Application. Materials Today: Proceedings, 5(PMME 2016), 789-795.

9. Hassan, A. R. (2009). Contact stress analysis of spur gear teeth pair. World Academy of Science, Engineering and Technology, 58(1), 597-602.

10. Hwang, S.-C., Lee, J.-H., Lee, D.-H., Han, S.-H., \& Lee, K.-H. (2013). Contact stress analysis for a pair of mating gears. Mathematical and Computer Modelling, 57(1-2), 40-49. 
11. Jabbour, T., \& Asmar, G. (2015). Tooth stress calculation of metal spur and helical gears. Mechanism and Machine Theory, 92, 375-390.

12. Karaveer, V., Mogrekar, A., \& Joseph, T. P. R. (2013). Modeling and finite element analysis of spur gear. International Journal of Current Engineering and Technology, 3(5), 2104-2107.

13. Khan, M. J., Mangla, A., \& Din, S. H. (2015). Contact Stress Analysis of Stainless Steel Spur Gears using Finite Element Analysis and Comparison with Theoretical Results using Hertz Theory. International Journal of Engineering Research and Applications, 5(4), 10-18.

14. Khdir, Y.-K., Kanit, T., Zaïri, F., \& Naït-Abdelaziz, M. (2014). Computational homogenization of plastic porous media with two populations of voids. Materials Science and Engineering: A, 597, 324-330.

15. Khdir, Y.-K., Kanit, T., Zaïri, F., \& Naït-Abdelaziz, M. (2015). A computational homogenization of random porous media: Effect of void shape and void content on the overall yield surface. European Journal of Mechanics-A/Solids, 49, 137-145.

16. Khdir, Y., Kanit, T., Zaïri, F., \& Nait-Abdelaziz, M. (2013). Computational homogenization of elasticplastic composites. International Journal of Solids and Structures, 50(18), 2829-2835.

17. Khdir, Y. K. (2016). Estimates for Linear hardening and Effective Yield Stress of Nano-Porous Media with Non-Uniform Distribution of Voids. ZANCO Journal of Pure and Applied Sciences, 28(2).

18. Lisle, T. J., Shaw, B. A., \& Frazer, R. C. (2017). External spur gear root bending stress: a comparison of ISO 6336: 2006, AGMA 2101-D04, ANSYS finite element analysis and strain gauge techniques. Mechanism and Machine Theory, 111, 1-9.

19. Miler, D., Žeželj, D., Lončar, A., \& Vučković, K. (2018). Multi-objective spur gear pair optimization focused on volume and efficiency. Mechanism and Machine Theory.

20. Narayankar, N. D., \& Mangrulkar, K. S. (2017). Contact Stress and Bending Stress Analysis of Spur Gear by Analytical Method. International Journal on Theoretical and Applied Research in Mechanical Engineering, 6(1-2), 1-3.

21. Quadri, S., \& Dolas, D. (2015). Contact Stress Analysis of Involute Spur gear under Static loading. International Journal of Scientific Research Engineering \& Technology, 4(5), 593-596.

22. Rajaprabakaran, V., \& Ashokraj, M. R. (2013). Spur gear tooth stress analysis and stress reduction. IOSR journal of mechanical and civil engineering, 38-48.

23. Rao, P., Sriraj, R., \& Farook, M. (2015). Contact Stress Analysis of Spur Gear for Different Materials using ANSYS and Hertz Equation. International Journal of
Modern Studies in Mechanical Engineering, 1(1), 45-52. 24. Rao, P. S., \& Vamsi, C. (2016). Contact Stress and Shear Stress Analysis of Spur Gear Using ANSYS and Theoretical. Int. J. of Modern Studies in Mech. Engineering, 2(2).

25. Ravindra, S. I. (2013). Static and Dynamic Analysis of High Contact Ratio Spur Gear Drive.

26. Sainath, I. A. Design of Spur Gear and its Tooth profile. Journal of Engineering Research and Applications (IJERA) ISSN, 2248, 9622. 